man would best leave them to him who is exceptional. It is the physically average man who does the world's work, and if he becomes physically incapacitated, as he may easily become if he tries to become physically exceptional, not only the individual but the world suffers. It is not only the teaching of physiology, but it is the teaching of common sense to avoid physical excess. Common-sense hygiene should have its place in a liberal education. What a liberal education should do for the individual is so well put by Huxley that I am tempted to quote his words:

That man has had a liberal education who has been so trained in youth that his body is the ready servant of his will, and does with ease and pleasure all the work that, as a mechanism, it is capable of; whose intellect is a clear, cold, logic engine, with all its parts of equal strength, and in smooth working order; ready, like a steam engine, to be turned to any kind of work, and spin the gossamers as well as forge the anchors of the mind; whose mind is stored with a knowledge of the great and fundamental truths of nature and of the laws of her operations; one who, no stunted ascetic, is full of life and fire, but whose passions are trained to come to heel by a vigorous will, the servant of a tender conscience; who has learned to love all beauty, whether of nature or of art, to hate all vileness, and to respect others as himself.

Physiology tells me that this is the education which we should give to our youth. Frederic S. Lee

Columbia UnIVERSity

\section{DEPARTMENTAL ORGANIZATION FOR THE REGULATION OF PHYSICAL INSTRUC- TION IN SCHOOLS AND COLLEGES FROM THE STANDPOINT OF HYGIENE ${ }^{1}$}

Physical instruction or physical education in the past has been handled largely

${ }^{i}$ An address delivered in a symposium on "The Regulation of Physical Instruction in Schools and Colleges, from the Standpoint of Hygiene," before Section K (Physiology and Experimental Medicine) of the American Association for the Advancement of Science, Baltimore, December 20, 1908. from the standpoint of physical exercise. Gymnastics, or calisthenics, or gåmes, or athletics have constituted the chief and often the only work done in physical instruction in many of our institutions. The word "gymnasium" has been and often is now, synonymous with the words "department of physical education." The objects of physical instruction have been predominantly those attainable through physical exercise. Many of our departments are even now interested mostly in bulk of muscle or in strength, speed, endurance and coordination; or in the development of a winning team or a star athlete; or in the perfection of bilateral symmetry and the production of grace of movement. And so we find the curriculum of the department including only, or chiefly, such individual and class work as may be handled from the standpoint of physical exercise. An anthropometric examination has been a common requirement because it has been assumed that by comparing the individual with the standard, his need for special developmental physical exercise would become apparent. He could then specialize more or less along certain lines of physical exercise and correct his deficiencies in form, symmetry, bulk or strength of muscle. Certain special medical data have been secured frequently because it was found that physical exercise might easily produce a serious effect upon unusually weak organs.

Further, the curriculum always provided some sort of work in physical exercise. This might be applied to the individual or to groups or classes. It consisted of mass drills or apparatus exercises, games, contests, swimming or athletic sports, or combinations of any two or more of these various phases of physical exercise. Special exercise was planned in many cases for those individuals who ap- 
peared to need special or corrective development.

The instructors selected to handle departmental work have been selected with more or less special reference to the chief objects which the departments might have in view. These objects were in some cases predominantly anthropometric. They were rarely widely hygienic or medical and they were nearly always narrowly hygienic or purely gymnastic or athletic. For these reasons, the special preparation of the instructor in physical instruction has been occasionally medical, occasionally hygienic, rarely physiological, often anthropometric and usually gymnastic and athletic.

As a result of these limitations in departmental scope and staff equipment, the achievements of physical instruction have been restricted to some of the anatomical, physiological, hygienic and psychological effects of exercise; and because of these same limitations, the faults of physical instruction have been numerous and destructive. The instructors have not often been men of academic training or of scientific or of professional training. Such equipment was not asked for, as a rule, and often could not have been paid for had it been offered. With inadequately trained instructors on the one hand-I will not say poorly trained, because many of them were superbly trained for special phases of physical exercise, but not for physical instruction-and on the other hand with the departmental scope limited to one or more phases of physical exercise, it has naturally followed that physical instruction has been judged to be unacademic and that academic men have been reluctant to permit its academic advancement.

Furthermore, these conditions have made collegiate physical instruction appear to be synonymous with gymnastic work, so that the Y. M. C. A. gymnasium, the church gymnasium, the factory gymnasium, the business man's gymnasium and the athletic club, are all classed popularly with the collegiate department and with each other. (It is not my purpose here to discuss relative merits and I must not be construed as deprecating the value of these gymnasiums, particularly those of the Young Men's Christian Association.)

Furthermore, this narrow departmental scope with its consequent limiting effect upon staff equipment, not only makes it impossible for the department to realize the broad health influences which we now believe belong to it, but it increases greatly the chances for physical injury to the individual student or pupil. Without a knowledge based upon a medical examination of the organic condition of the individual, it is impossible to plan his work wisely and safely. Without a sound knowledge of the physiology of exerciseand this includes the major part of all human physiology-it is unsafe to undertake to administer exercise to large groups of boys or men among whom unsuspected anatomical and consequent physiological weakness or abnormality may be present. Clearly, many of our teachers in physical instruction have not been adequately trained for even the relatively narrow field of physical exercise to which physical instruction has so long been confined. And it is no wonder that complaint has arisen from physician, physiologist, hygienist, educator and layman. It is no wonder that concrete examples of medical, hygienic and physiological error may be cited. It is no wonder that positive injury has been done to individuals. It is remarkable, rather, that so little injury has followed in the wake of these conditions.

On the other hand, there have always been thoughtful men in physical education who have held that the chief object 
of their work was the development and maintenance of health. "A sound mind in a sound body"-this is an old battle cry-means a healthy mind in a healthy body. Some of our oldest directors have taken this position, though forced by circumstances and by training to rely almost wholly upon physical exercise for the accomplishment of their objects. These men have felt that physical instruction is bigger than physical exercise, and that physical exercise can not alone secure the desired effects on health. They have felt that physical instruction is concerned with physical health; that physical health is fundamental to normal physiological activity, whether that activity be expressed as locomotion, circulation, respiration, digestion, cerebration or any other organic function. We know that the physical health of the human body depends upon the health of the tissue cells of which the human body is composed. The health of these cells depends absolutely upon their nourishment, their exercise, their rest, the proper disposition of their excretions and the other products of their activities, and upon a reasonable freedom from the influence of disease-producing agents. The neglect of any one of the requisites may destroy the good effects of the proper observance of the others. And it follows that the physical health of the human body may be secured and conserved only by the observance of the several fundamental laws that operate in the production of health in the tissue cells. These laws are concerned with nutrition, excretion, exercise, rest, respiration, cleanliness and protection against disease. Their uniform observance means physical health. The neglect of any one law means failure in the effort to secure and conserve health, even though these other laws may have been properly observed. No man may expect good physical condition and consequent health if he sleeps too little, or if he ruins his digestion and thus starves his tissues, or if he takes no exercise, or if he neglects his excretions, or breaks any other of these laws.

With these facts in mind a considerable number of men interested, feel that a department of physical instruction must teach the theory and develop the practise of these several fundamental laws of health in order to approximate the object for which such a department exists. It can not afford to neglect any one of these fundamental laws and it can not afford to overestimate any one of these laws.

We find evidences of this conception of the broad scope of physical instruction in many of our colleges. A year ago in the Society of College Directors of Physical Instruction, there were forty members, of whom thirty-two had academic or professional degrees. These thirty-two men have sixty-one degrees. Less than a year ago at the second congress of the American School Hygiene Association, Meylan, of Columbia University, reported that thirty-one out of thirty-two college departments of physical instruction which replied to his questionnaire were giving courses in hygiene. This means that some of these departments are in the hands of men with academic sympathies, men who are trained medical experts, men who are experienced hygienists; and that these men combine this equipment with that of a practical experience in the technical procedures of gymnasium work. The departments under these men are being organized somewhat as follows: First, all students or pupils are in many places required to undergo a medical examination. The tendency of the modern college and high school is to require this examination of all individuals whether they are planning to go into athletic or gymnastic work or not. In most colleges opportunities for 
medical consultation are provided. In some colleges and high schools, frequent medical inspections are required. On the basis of these examinations, inspections and consultations, the school life and departmental activities of the individual are regulated. This influence goes so far in some instances as to debar the individual from attendance because of his physical condition. In any event, his physical exercise is planned in conformity with these medical findings, so that the possibility of injury to weak organs through excess exercise influences is greatly minimized.

Second: A hygienic and sanitary supervision is exercised in some institutions. This supervision is closely related to the medical supervision. In fact, they can not be separated entirely. This combined supervision, medical and hygienic, regulates the physical exercise applied in the department. It selects and grades the drills and exercises in the various courses with reference to desirable physiological, anatomical and mental effect. It plans the special work for the special cases with special reference to the conditions that are found on medical examination. Further, it enforces a practical application of hygiene and sanitation throughout the department and often throughout the other departments of the high school or college. Such a supervision can and does enforce bodily cleanliness in the exercising hall; enforces clean gymnasium suits and towels; and enforces regulations relative to spitting and other nuisances in locker rooms, hallways and corridors; and regulates the sanitation of the toilet rooms, shower baths, swimming pool and so on. Pupils and students whose personal hygiene is obnoxious may be required either to improve their hygiene or leave the institution. This influence may easily extend to secure an improvement of the student's home surroundings, because his own hygiene can hardly surpass that of his environment.

It can be easily seen that this medical and hygienic supervision secures: first, protection from contagion; second, discovery of and expert advice concerning remediable physical defects; third, regulation of exercise in conformity with the organic limitations of the individual; fourth, the application of the laws of hygiene and sanitation to the individual and his institutional surroundings; fifth, a habituation to hygienic practises which is likely to influence the individual and through him his surroundings for the remainder of his existence.

A third phase of this modern departmental organization provides for instruction concerning the simple fundamental laws of human health. Personal hygiene, general hygiene and sanitation are being taught in these departments. Courses are given on such subjects as "Ways and Means of Securing and Conserving Health," "The Influence of Common Abnormalities and Habits of Health," "The Causes of Diseases," "Carriers of Disease," "Defenses against Diseases" and "The Nature of Some Common Diseases." These courses teach some of the main facts of nutrition, exercise, rest, excretion, bathing and disease, so that young men may carry away an intelligent policy of personal health control.

The fourth division of departmental organization is that which provides instruction in the various phases of physical exercise, including mass drills, apparatus exercises, swimming, and indoor and outof-door games, sports and play. This work is being carefully graded. It is taught with direct reference to its influence on the health and character of the individual and therefore with a close adherence to the laws of physiology, hygiene, psychology and medicine as we now understand them. 
Mass of muscles, strength, speed, endurance and coordination are secured incidentally. They are indeed often desirable, but are not the main objects of such work. These various phases of physical exercise are planned with reference to their primary influence on tissue health and their inevitable secondary influence on functional efficiency, such as voluntary muscular contraction, circulation, respiration, digestion, assimilation and cerebration. They do their heavy share of the work necessary in order to turn out men of health, men of courage, men of self-reliance, men of selfrespect, men who think on their feet and act on their thoughts, and men who have learned the value of combined effort and the subordination of the individual interest to that of the group.

As an example of departmental organization in these four phases of physical instruction, permit me to cite a department that has come under my close observation. This department is in a college in which the combined academic and collegiate attendance reaches about four thousand. The department of physical instruction there is given a medical and hygienic supervision over the entire student body. A medical examination is required of all entering academic and collegiate students. The medical inspections are required each half year of all academic pupils and of all freshmen and sophomores. Medical consultations are open to all students on their own volition or on request of their instructors. All candidates for athletic teams undergo a special medical examination before admission to competition or training. Upon recommendation from the department, all students whose physical condition is a menace to their companions are debarred from attendance until the complaint is removed. All students whose physical condition requires it, are given special exercise during the terms in which they are required to attend classes in the department.

A special hygienic and sanitary supervision is exercised over the students in the department and over the departmental building and all of its subdivisions.

Instruction in hygiene is given in six courses to each of the six classes that are required to take work in the department. These courses cover "The Ways and Means of Securing and Conserving Health," first term; "The Influence of Certain Abnormalities on Health," second term; "Some of the Causes of Disease," third term; "The Carriers of Disease," fourth term; "Defenses against Disease," fifth term; and "The Nature of Some Common Diseases," sixth term.

Instruction in physical exercise is given to these six classes. The mass drills are carefully graded throughout the six terms. The apparatus work is graded during the last four terms required in the department, that is, during the freshman and sophomore years. Graded requirements in swimming are in operation in each of the courses in the department and are classified under "Apparatus Work." No out-of-door work is provided, so that this seriously important phase of exercise is neglected. Certain games are taught in the department.

A typical class hour is divided as follows: first period, floor talk on health; second period, mass drill; third period, apparatus work.

Written examinations and practical tests are required every month and final written and practical examinations are applied each term. The records of these examinations are filed with those from the other departments with the secretary of the faculty as term and final examination marks; credits are given for the work.

Let me summarize the main points of my paper as follows: First: Physical instruction has been handled largely from the 
standpoint of physical exereise; this standpoint has limited the scope of the department to the possibilities that lie within the range of physical exercise. It has restricted the preparation required of teachers of physical instruction to those subjects or experiences bearing on some one or more phases of physical exercise, and it has made possible and deserved many criticisms because of its unacademic character and its opportunities for the commission of injury to individuals.

Second: There have always been a few directors of physical instruction who feel that their field of work is larger than that of physical exercise, and that it is concerned with human health.

Third: Physical instruction is now being handled more and more from the standpoint of human health. This point of view broadens the scope of the department so that it includes medical, sanitary and hygienic supervision and instruction concerning the simple fundamental laws of health and the various phases of physical exercise. This broader departmental scope necessitates the employment of experts upon the staff whose special training has fitted them for medical, hygienic and sanitary supervision and instruction as for instruction in the various and important phases of gymnasium and athletic work.

In conclusion, gentlemen, permit me to state that we who are interested in these tendencies in physical instruction believe they are tendencies in the right direction. We believe that our professional and pedagogical aim has in view the achievement and conservation of human health through the regulation of physical instruction from the standpoint of hygiene. We believe that this broad field belongs logically to us. We believe that if we can develop and conserve health in human beings, and teach them how to exercise an intelligent policy of personal health control, we shall have utilized whatever special scientific, medical, hygienic and pedagogical training we may have, for the best interests of humanity of which we are a part and of the world in which we live.

Thomas A. Storey

College of the City of New Yorr

\section{THE CARNEGIE FOUNDATION FOR THE ADVANCEMENT OF TEACHING}

THe annual reports of President Eliot to the corporation of Harvard University have in certain respects been the most interesting educational documents of past years; their place will now be taken by the reports of President Pritchett of the Carnegie Foundation. In these reports and in the intervening bulletins, there are not only given lucid and complete accounts of the activities of an institution of vast importance for higher education, but also careful studies of the educational system of the country. In this respect the foundation sets an example to the General Education Board, which keeps for its private use the information that it collects, and does not even publish the financial statements that should be required by law from every corporation, and first of all from those exempted from taxation.

President Pritchett's third annual report, which covers the year ending September 30,1908 , shows that the new grants made during the year amounted to $\$ 113,765$. The grants in force amounted to $\$ 303,505$, an increase of $\$ 101,360$ over the preceding year. Should this increase continue for two further years, the income of the foundation would be exhausted. The retiring allowances in force were: On basis of age, 86 ; on basis of length of service, 81 ; for disability, 15; to widows of professors, 29 . The average age of those retired for length of service is 65.7 years, so that it would appear that more than half of them are entitled to retirement for age. The aver- 